\title{
Special seat reserved for Hindus, Sikhs in Afghan Parliament
}

by PTI

Wednesday, 04 September 2013 17:01

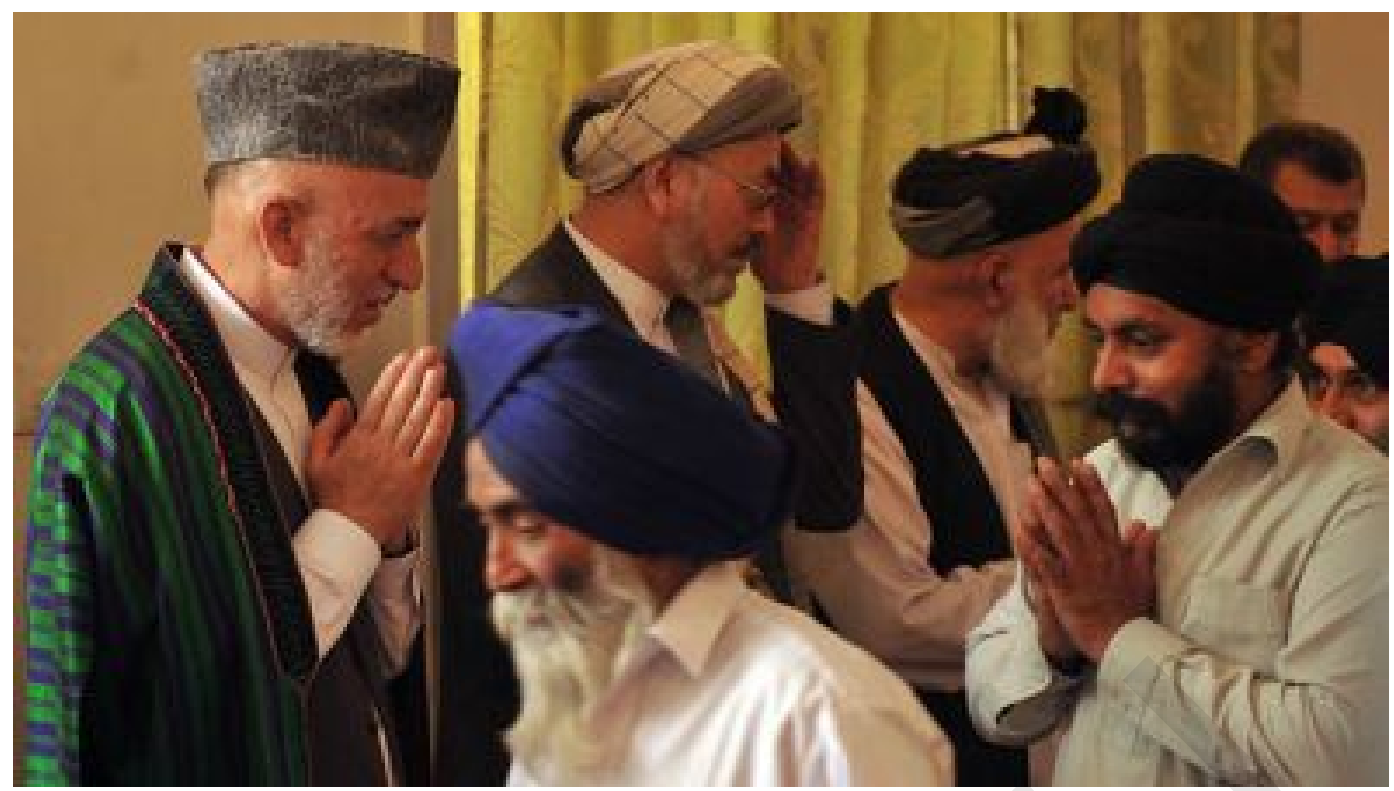

Kabul, Sep 4: President Hamid Karzai today issued a historic legislative decree reserving a special seat for Sikh and Hindu Afghan nationals in the lower house of the country's Parliament.

Karzai, through the legislative decree, approved the Cabinet amendments of August 26, 2013, to the Election Law, designating a particular seat in the Wolesi Jirga for Sikh and Hindu nationals, according to a statement from the office of the President.

In the Presidential decree, Karzai assigned the Ministers of Justice and Parliamentary Affairs to submit the decree within 30 days after the National Assembly of Afghanistan resumes its first session.

The decree further says that the amendments to the Election Law came into force upon signature by the President and shall be published along with the relevant Cabinet resolution in the official gazette.

The National Assembly of Afghanistan is a bicameral body, comprising two chambers, Wolesi Jirga or the lower house with 249 seats and Meshrano Jirga or the Upper House with 102 seats. 
Special seat reserved for Hindus, Sikhs in Afghan Parliament

by PTI

Wednesday, 04 September 2013 17:01

The reserved seat has been designated to the lower house which will now have 250 members.

Karzai's decision has come after lawmakers declined to reserve a special seat for Hindus and Sikhs in the law.

The Afghan President has the power to issue legislative decrees when the Parliament is on vacation. 